\title{
Retinal thickness in black and Indian myopic students at the University of KwaZulu-Natal
}

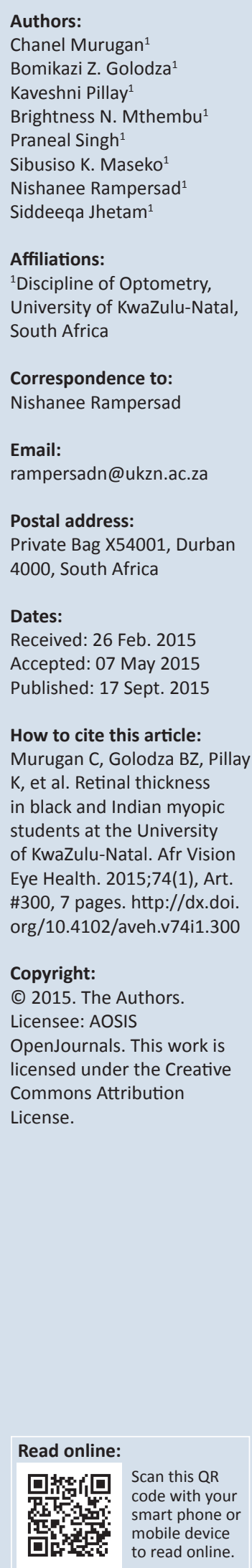

Background: It has been suggested that retinal thickness varies with demographic variables. Understanding the influence of demographic variables on retinal thickness could improve our knowledge of risk factors for retinal pathologies. Previous studies have focused exclusively on white and African-American populations, with limited attention to black and Indian populations.

Aim: To compare retinal thickness in black and Indian myopic students at the University of KwaZulu-Natal (UKZN).

Methods: A cross-sectional comparative research design was used. The study was conducted at UKZN, Westville campus. Retinal thickness was measured in 80 healthy myopic students using the Fourier/spectral domain iVue 100 optical coherence tomographer. Retinal thickness measurements of the right and left eyes showed significant correlations, therefore data from only the right eyes were analysed. Racial and gender variations in retinal thickness of the nine Early Treatment Diabetic Retinopathy Study (ETDRS) segments were assessed.

Results: The mean central foveal thickness in black participants was $238 \mu \mathrm{m}$ compared with $243 \mu \mathrm{m}$ in Indian participants $(p=0.06)$. Indian participants had thicker parafoveal thickness measurements whilst black participants had thicker perifoveal thickness measurements. Male participants had thicker retinal thickness measurements in all nine ETDRS segments than female participants. Central foveal thickness showed no significant correlation with spherical equivalent $(r=-0.14, p>0.05)$ or axial length $(r=0.09, p>0.05)$.

Conclusion: The average central foveal thickness was slightly thinner in black and female participants than in Indian and male participants. Optometrists and ophthalmologists should consider these differences when evaluating black and Indian individuals with foveal retinal diseases.

\section{Introduction}

The retina is a light-sensitive structure forming the innermost layer of the eye and consists of various cells (photoreceptor cells, ganglion cells, glial cells and interneurons). ${ }^{1,2}$ Assessment of the thickness and structural organisation of the retina is important for the detection, management and follow-up of various retinal diseases. Traditional methods for evaluation of the retina include fundus photography, slitlamp biomicroscopy with retinal lens, and fluorescein angiography. ${ }^{3}$ However, these methods only provide a subjective and qualitative retinal assessment.

Optical coherence tomography (OCT) is a new, non-invasive method that allows high-resolution cross-sectional imaging and quantitative assessment of retinal thickness. ${ }^{4}$ OCT works on a principle similar to ultrasound except that reflected light waves are measured instead of sound waves. Early OCT systems (e.g. the Stratus OCT) used time-domain detection and achieved scanning speeds of 400 A-scans per second with $8 \mu \mathrm{m}-10 \mu \mathrm{m}$ axial resolution. ${ }^{5,6}$ Since its introduction in 1991 by Huang et al., ${ }^{4}$ OCT technology has undergone significant improvements that have resulted in faster scanning speeds, improved eye movement tracking and increased resolution. The newer systems, called Fourier/spectral domain OCTs, provide faster scanning speeds (more than 20000 A-scans per second), higher sensitivity and improved image axial resolution $(5 \mu \mathrm{m}-7 \mu \mathrm{m}){ }^{5,6,7}$ As a result of its superior qualitative and quantitative retinal assessments, OCT is being widely used to screen, diagnose and monitor the progression of retinal diseases. . $^{5,9,9,10,11}$

Several studies suggest that retinal thickness varies with race $\mathrm{e}^{12,13,14,15,16}$ and gender, ${ }^{12,17,18}$ whereas other studies ${ }^{5,19,20}$ report no such variation. Understanding the influence of these demographic variables on retinal thickness could improve understanding of possible mechanisms and risk factors for certain retinal pathologies. This knowledge is necessary as the prevalence of retinal 
pathologies such as retinopathy of prematurity, ${ }^{21}$ agerelated macular degeneration, ${ }^{22,23}$ glaucoma ${ }^{24,25}$ and diabetic retinopathy ${ }^{26}$ varies in different race groups.

Previous studies that investigated racial variations in retinal thickness have some limitations. Firstly, many studies $7,13,14,16,18$ focused exclusively on white and African-American populations, with limited attention to the South African black and Indian populations. We believe that normative data on retinal thickness measurements in black and Indian populations may provide a useful baseline for future research studies investigating pathological retinal changes in these populations. Secondly, the OCT devices used in some studies ${ }^{12,13,14,15}$ were the older time-domain devices which have poorer repeatability and lower resolution and scanning speeds than the newer Fourier/spectral domain devices. ${ }^{6,727}$ Furthermore, some studies failed to take into account the influence of age and refractive error on retinal thickness. Retinal thickness decreases with increasing age, ${ }^{17,28}$ consequently, the results reported might have been influenced by including a larger age range of study participants. By including participants with both myopia and hyperopia, the results reported might also have been biased because refractive error influences retinal thickness. ${ }^{29,30}$ Finally, in some previous studies, ${ }^{5,13,16}$ the sample sizes ranged from 14 to 50 participants, which might have been too small to detect a difference in retinal thickness.

In the present study, we conducted a comparative evaluation of retinal thickness in a cohort of 80 black and Indian myopic students aged between 18 and 24 years. The main hypothesis was that retinal thickness measurements would vary with race and gender.

\section{Methodology}

The study (reference number SHSEC 038/13) was approved by the Research and Higher Degrees Committee of the School of Health Sciences, University of KwaZulu-Natal (UKZN). All ethical guidelines were adhered to during the study and written informed consent was obtained from all participants after explaining the nature and procedures involved in the study. The study employed a cross-sectional comparative research design and was conducted at UKZN's Westville campus. The study population included black and Indian UKZN students at the Westville campus. Convenience sampling was used to recruit 80 myopic (40 black and 40 Indian) participants aged between 18 and 24 years. Participants with hyperopia, unaided or best corrected visual acuity worse than 6/6, intraocular pressure greater than $21 \mathrm{mmHg}$, associated systemic and/or ocular diseases and currently on medication were excluded.

The following screening procedures were conducted to assess participants' eligibility according to the inclusion criteria: case history (medical and ocular), visual acuity, autorefraction (Nidek AR-1), slit lamp biomicroscopy, ophthalmoscopy and non-contact tonometry (Nidek NT530P). Thereafter data collection procedures were performed for eligible participants. Subjective refraction (starting with the autorefraction results) was performed to determine the myopic refractive error. The myopic spherical equivalent was calculated. The sphere power plus half the negative cylindrical power constituted the final prescription. ${ }^{31}$ To ensure standardisation of refractive error results, all subjective refractions were performed by only one clinician.

Central corneal power, along the two principal meridians (K1 and K2), was measured using the Oculus keratograph. The Oculus keratograph has been used previously to assess corneal topography and is reported to be as reliable as other keratographs. ${ }^{32,33}$ Axial length was measured using the Nidek US-500 A-scan ultrasound device which has been used in other studies. ${ }^{34,35}$

Retinal thickness at the macula was scanned and measured using the Optovue iVue 100 OCT. This OCT device has a scanning speed and axial resolution of 25000 A-scans per second and $5 \mu \mathrm{m}$ respectively. ${ }^{36}$ Retinal thickness measurements are dependent on the algorithms used by the OCT device to detect the anterior and posterior retinal surfaces. The iVue 100 OCT device has a pre-programmed algorithm that defines the retinal pigment epithelium as the outer limit of the retina and the inner limiting membrane as the inner limit. Retinal thickness is thus automatically determined as the distance between these two boundaries.

The retinal map scan protocol which consists of a raster pattern of 13 horizontal $(6 \mathrm{~mm})$ line scans of 512 A-scans and 7 horizontal $(6 \mathrm{~mm})$ line scans of 1024 A-scans within the central $1.5 \mathrm{~mm}$ vertical zone was used. ${ }^{36}$ When capturing the retinal map scans, the internal fixation target was used and the location of the participant's eye and corresponding retina was monitored using the real-time image displayed on the laptop screen. Scans with quality indices $<40$, or labelled as poor on the laptop screen display, were repeated in accordance with the manufacturer's recommendations. ${ }^{36}$

The retinal map scan protocol displays average retinal thickness in each of the nine segments of the macular map as defined by the Early Treatment Diabetic Retinopathy Study (ETDRS). ${ }^{37}$ Central foveal thickness is defined as the average thickness in the central $1 \mathrm{~mm}$ ring (Figure 1). The inner and outer rings, of $3 \mathrm{~mm}$ and $5 \mathrm{~mm}$ diameter, correspond to the parafoveal and perifoveal regions respectively. The parafoveal and perifoveal regions are divided into four quadrants (superior, inferior, nasal and temporal) (Figure 1). The average retinal thickness in the central, parafoveal and perifoveal areas (nine segments) are presented accordingly in a retinal map using a false-colour topographic image display (Figure 1).

It is important to note that previous studies ${ }^{38,39,40}$ have demonstrated high levels of repeatability and reproducibility of OCT devices in measuring macular retinal thickness. Corneal power, macular retinal thickness and axial length measurements were each performed by one clinician, to 


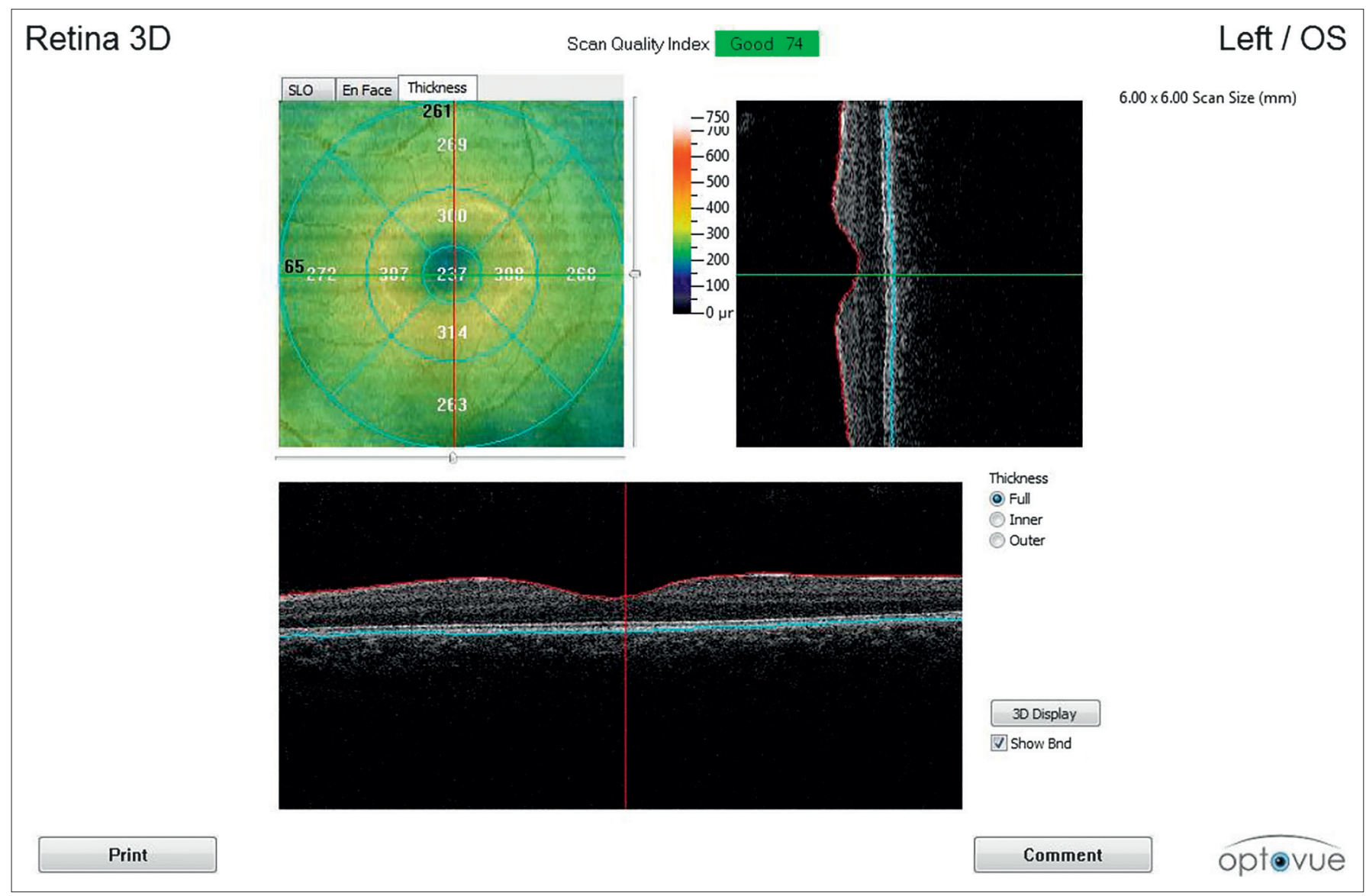

Source: Modified screen shot of a participant's results with the optical coherence tomography device.

FIGURE 1: Retinal map display showing the mean retinal thickness $(\mu \mathrm{m})$ in each of the nine segments of the Early Treatment Diabetic Retinopathy Study macular map.

ensure standardisation, where three measurements were recorded and the average computed.

Data were captured using Microsoft Excel and analysed with the Statistical Package for Social Science (SPSS) software (version 21). Normality of the data was assessed using the Shapiro-Wilk's test and graphical inspection of the retinal thickness histograms. Pearson's correlation coefficients were used to assess interocular symmetry and relationships between ocular characteristics. The results are presented in segments as mean \pm standard deviation (s.d.). Independent sample $t$-tests were used to assess racial and gender differences in retinal thickness. Significance was set at the $95 \%$ confidence level ( $p$ value $\leq 0.05$ ).

\section{Results}

Participants' ages ranged from 18 to 24 years with the mean age of the black and Indian participants being 21.08 \pm 1.9 years and $21.10 \pm 1.4$ years respectively $(p>0.05)$. The preliminary statistical analysis revealed that macular retinal thickness measurements of the right and left eyes showed significantly high levels of symmetry. Central foveal thickness measurements of the right and left eyes were highly correlated $(r=0.906, p<0.01)$. This interocular symmetry trend was also observed for the other eight ETDRS segments (all $p$ values $<0.01$ ). Our results are in agreement with previous studies which demonstrated significant interocular
TABLE 1: Means and standard deviations for age and ocular characteristics of the black $(n=40)$ and Indian $(n=40)$ myopic participants.

\begin{tabular}{lcc}
\hline Age and ocular characteristics & Black & Indian \\
\hline Age (years) & $21.08 \pm 1.9$ & $21.10 \pm 1.4$ \\
Spherical equivalent (D) & $-1.48 \pm 1.1$ & $-2.42 \pm 2.2 \dagger$ \\
Intraocular pressure (mmHg) & $13.23 \pm 1.9$ & $13.68 \pm 1.5$ \\
Corneal power: K1 (D) & $42 \pm 1.8$ & $43 \pm 1.5 \dagger$ \\
Corneal power: K2 (D) & $43 \pm 1.6$ & $44 \pm 1.3 \dagger$ \\
Axial length (mm) & $23.35 \pm 0.7$ & $23.18 \pm 0.9$ \\
Central foveal thickness $(\mu \mathrm{m})$ & $238 \pm 28$ & $243 \pm 18$ \\
\hline$\dagger, p$ value $\leq 0.05$, independent sample $t$-test. & &
\end{tabular}

symmetry for macular retinal thickness measurements. ${ }^{7,14,29}$ As a result of this similarity, data from only the right eyes of the 80 participants were analysed.

Table 1 summarises the demographic characteristics of the study participants. Spherical equivalent refractions ranged from $-0.25 \mathrm{D}$ to $-8.25 \mathrm{D}$ for all participants. The spherical equivalent refractions ranged from $-0.25 \mathrm{D}$ to $-4.25 \mathrm{D}$ and $-0.25 \mathrm{D}$ to $-8.25 \mathrm{D}$ for the black $(n=40)$ and Indian $(n=40)$ participants respectively. Axial length measurements ranged from $21.14 \mathrm{~mm}$ to $25.92 \mathrm{~mm}$. Indian participants were on average significantly more myopic with steeper corneal powers than were black participants. Black participants had lower intraocular pressures, longer axial lengths and thinner central foveal thickness measurements than Indian participants. However, these differences in ocular characteristics were not statistically significant (Table 1). 
TABLE 2: Retinal thickness $(\mu \mathrm{m})$ in each Early Treatment Diabetic Retinopathy Study segment by race and gender indicated with means.

\begin{tabular}{|c|c|c|c|c|c|}
\hline Macular region & ETDRS quadrant & Black $(n=40)$ & Indian $(n=40)$ & Male participants $(n=40)$ & Female participants $(n=40)$ \\
\hline Central foveal region (1 $\mathrm{mm}$ ring) & - & 238 & 243 & 245 & 236 \\
\hline \multirow[t]{4}{*}{ Parafoveal region (3 mm ring) } & Superior & 310 & 312 & 314 & 308 \\
\hline & Inferior & 305 & 308 & 310 & 303 \\
\hline & Nasal & 309 & 313 & 318 & $305 \dagger$ \\
\hline & Temporal & 296 & 296 & 300 & 292 \\
\hline \multirow[t]{4}{*}{ Perifoveal region (5 mm ring) } & Superior & 288 & $277 \dagger$ & 288 & $277 \dagger$ \\
\hline & Inferior & 275 & 270 & 273 & 272 \\
\hline & Nasal & 294 & 291 & 295 & 290 \\
\hline & Temporal & 270 & $259 \dagger$ & 264 & 264 \\
\hline
\end{tabular}

ETDRS, Early Treatment Diabetic Retinopathy Study.

$\dagger, p$ value $\leq 0.05$, independent sample $t$-test.

Axial length was significantly associated with spherical equivalent $(r=-0.35, p<0.05)$. Central foveal thickness showed no significant correlation with spherical equivalent $(r=-0.14, p>0.05)$ or axial length $(r=0.09, p>0.05)$. Also, intraocular pressure was not correlated with central foveal thickness $(r=0.08, p>0.05)$.

Table 2 presents the retinal thickness measurements stratified for race and gender. The central foveal region was thinnest followed by the perifoveal region, with the parafoveal region being thickest in both race and gender groups. The central foveal thickness in black participants was $238 \mu \mathrm{m}$ compared with $243 \mu \mathrm{min}$ Indian participants $(p=0.06)$. Indian participants had thicker parafoveal thickness measurements than black participants in all quadrants except temporal (Table 2). This thickness difference in the parafoveal region ranged between $2 \mu \mathrm{m}$ and $4 \mu \mathrm{m}$ and was found to be insignificant $(p>0.05)$. Within the parafoveal region, the temporal quadrant was thinnest and had an equal measurement $(296 \mu \mathrm{m})$ for both black and Indian participants. Black participants had thicker perifoveal thickness measurements than Indian participants in all four quadrants. Within the perifoveal region, the thickness difference ranged between $3 \mu \mathrm{m}$ and $11 \mu \mathrm{m}$ with only the superior $(p<0.05)$ and temporal $(p<0.05)$ quadrants showing statistical significance (Table 2 ). In both races, the superior and nasal quadrants were thicker than the inferior and temporal for the parafoveal and perifoveal regions.

The central foveal thickness in female participants was $9 \mu \mathrm{m}$ thinner than that of male participants $(236 \mu \mathrm{m}$ versus $245 \mu \mathrm{m}, p>0.05)$. Furthermore, male participants had slightly thicker parafoveal and perifoveal thickness measurements in all quadrants than female participants; but only the parafoveal nasal and perifoveal superior quadrants with thickness differences of $13 \mu \mathrm{m}$ and $11 \mu \mathrm{m}$ respectively reached statistical significance $(p<0.05)$. In the parafoveal region, the nasal and superior quadrants were thickest for male and female participants respectively, with the temporal quadrant being the thinnest. In the perifoveal region, the nasal and temporal quadrants were the thickest and thinnest respectively for both male and female participants.

\section{Discussion}

In the present study, it was found that retinal thickness varies between black and Indian myopic students at UKZN. Black participants had slightly reduced central foveal thickness compared with Indian participants $(238 \mu \mathrm{m}$ versus $243 \mu \mathrm{m})$ but the difference was not statistically significant $(p=0.06)$ although nearly so. Racial differences in foveal retinal thickness measurements have been reported in previous studies.,13,15,16,41 Asefzadeh et al. ${ }^{13}$ reported thinner foveal retinal thickness in black $(204 \mu \mathrm{m})$ than in white people $(228 \mu \mathrm{m})$. Kashani et al. ${ }^{15}$ reported a similar trend with reduced central foveal thickness in African-American (181 $\mu \mathrm{m})$ compared with white $(200 \mu \mathrm{m})$ and Hispanic people $(195 \mu \mathrm{m})$. Grover et al. ${ }^{16}$ showed significantly higher retinal foveal thickness measurements in both white $(273 \mu \mathrm{m})$ and Asian people $(280 \mu \mathrm{m})$ than in black $(257 \mu \mathrm{m})$ people. Wagner-Schuman et al. ${ }^{7}$ found significantly reduced foveal retinal thickness measurements in African/AfricanAmerican $(245 \mu \mathrm{m})$ compared with white people $(266 \mu \mathrm{m})$. This trend was consistent with the finding of Harb et al. ${ }^{41}$ who also demonstrated significantly thinner foveal thickness in African-American $(242 \mu \mathrm{m})$ than in white $(260 \mu \mathrm{m})$ and Hispanic people $(251 \mu \mathrm{m})$.

The exact reason for retinal thickness measurements varying with race is unknown. However, Chauhan and Marshall ${ }^{42}$ suggested that it may be related to varying amounts of melanin present in the retinal pigment epithelium in the different race groups. Melanin is known to absorb light ${ }^{43}$ which alters the reflected light signal as interpreted by the OCT software. It has been suggested that higher amounts of melanin in darkly pigmented individuals weaken the OCT light signal and therefore results in reduced retinal thickness measurements. ${ }^{42}$ An alternative explanation for these differences in retinal thickness may be related to the characteristics (depth and diameter) of the foveal pit. ${ }^{7}$ Wagner-Schuman et al. ${ }^{7}$ found that African/AfricanAmerican people had significantly deeper foveal pits $(15 \mu \mathrm{m})$ and wider foveal diameters $(190 \mu \mathrm{m})$ than those of white people. The researchers further proposed that these structural differences may account for the retinal thickness differences observed in different race groups. ${ }^{7}$ However, further research studies are needed to validate these claims to confirm precisely which retinal layers and characteristics may be involved.

The central retinal thickness measurements found in the present study are different from previous studies obtained using other OCT devices on other Indian and black 
populations. In the present study, using the iVue 100 OCT device, the central foveal thickness for black participants was $238 \mu \mathrm{m}$ which is much higher than that found in other black populations ${ }^{14,15}$ scanned with the OCT3 device. In contrast, Gover et al. ${ }^{16}$ examined 50 black adults with the Spectralis OCT and showed central foveal thickness to be $257 \mu \mathrm{m}$. In the present study, central foveal thickness for Indians was $243 \mu \mathrm{m}$ which is greater than that reported for other Indian populations. ${ }^{3,19}$ Adhi et al. ${ }^{3}$ found central foveal thickness measurements of $229 \mu \mathrm{m}$ using a Topcon OCT device. In another study, Tewari et al. ${ }^{19}$ investigated retinal thickness in 170 Indian people and reported measurements of $181 \mu \mathrm{m}$ for the central fovea.

This difference in retinal thickness found in the present study between black and Indian participants versus other similar populations may be the result of various factors. Differences in study methodologies, especially regarding the type of OCT devices and scan protocols, used to measure retinal thickness could account for the variation observed. Several studies ${ }^{5,6,44}$ caution against comparing retinal thickness measurements across studies as OCT devices use differing algorithms to automatically detect the outer and inner boundaries used to measure retinal thickness. The inner limiting membrane is used as the inner boundary in all OCT devices ${ }^{45}$ whilst the outer boundary varies, depending on the OCT device software. For example, the iVue OCT device defines the retinal pigment epithelium as the outer boundary whilst the Stratus OCT delineates the junction of the inner and outer segments (OS/IS) of the photoreceptors as the outer boundary. ${ }^{5,646}$ It is also possible that the newer OCT systems demonstrate varying retinal thickness measurements because of improved resolution and scanning speeds. ${ }^{5,6}$

For both black and Indian people, it was noted the central fovea was the thinnest, followed by the perifovea, with the parafovea being the thickest. The same trend has been reported by many studies that have used OCT technology to measure retinal thickness in Norwegian, ${ }^{47}$ British, ${ }^{48}$ Chinese, ${ }^{49,50}$ Korean, ${ }^{17}$ Pakistani $^{3}$ and Bulgarian ${ }^{45}$ populations. The central fovea is thinner than the surrounding retina (parafoveal and perifoveal regions) owing to the anatomical arrangement of retinal layers, with the thickness of the central fovea not including the retinal nerve fiber layer. The temporal and nasal quadrants were thinnest and thickest respectively for the perifoveal region which is consistent with reports from other studies. ${ }^{5,17,49,50}$ Mitkova-Hristova and Konareva-Kostyaneva ${ }^{45}$ suggested that the arrangement of fibres in the papillo-macular region may account for this trend in quadrant retinal thickness measurements.

In the present study, male participants had higher retinal thickness measurements in all nine ETDRS segments than female participants. This gender-related difference in retinal thickness is consistent with reports from previous studies $^{3,12,14,15,17,18}$ which suggest the influence of gender on retinal thickness. The present study's results are in contrast to some studies that have reported no difference in retinal thickness measurements between male and female participants. ${ }^{5,16,51}$ A possible explanation for this inconsistency could be the small sample sizes associated with these studies that reported no gender differences in retinal thickness measurements. Grover et al. ${ }^{16}$ measured retinal thickness on 50 participants (26 male and 24 female) with a Spectralis OCT. Sull et al. ${ }^{5}$ measured retinal thickness on 40 participants (21 male and 19 female) with a Stratus OCT. Chan et al. ${ }^{51}$ measured retinal thickness on 37 participants (11 male and 26 female) with an OCT3 device. By virtue of the small sample sizes, these studies might have had insufficient power to detect differences in retinal thickness between male and female participants. Further analysis of the results reported in these studies revealed retinal thickness differences of $3 \mu \mathrm{m}$ and $8 \mu \mathrm{m}$ between male and female participants, which is similar to the results observed in the present study (average thickness difference of $7 \mu \mathrm{m}$ ).

The relationship between refractive error and central foveal thickness is inconsistent as contradictory results have been reported in the literature. Some studies ${ }^{14,17,19,49}$ have found that myopic refractive error has no effect on retinal thickness whilst other studies ${ }^{30,41,52,53}$ have reported significant correlations. The present study is in agreement with the former group of studies and found no relationship between myopic refractive error and retinal thickness. Previous studies ${ }^{30,41,52,53}$ which have found significant correlations between retinal thickness and myopic refractive error have reported greater mean spherical equivalents. Sato et al. ${ }^{30}$ measured retinal thickness with a Spectralis OCT and reported a mean refractive error of -3.30 D. Harb et al. ${ }^{41}$ measured retinal thickness with a RTVue OCT and reported a mean refractive error of $-5 \mathrm{D}$. $\mathrm{Wu}$ et al. $^{52}$ measured retinal thickness with a third-generation OCT and reported a mean refractive error of -9.27 D. Since the mean spherical equivalent in this study was found to be considerably smaller (-1.95 D), this may account for the lack of relationship observed compared with other studies.

It is theorised that eyes with longer axial lengths (myopic refractive errors) have thinner retinal measurements than do emmetropic eyes. ${ }^{54,55}$ In the present study, we found that axial length had no effect on central foveal thickness. This is consistent with the findings of previous studies ${ }^{14,17,56}$ that also report no relationship. In the present study, no significant correlation between intraocular pressure and retinal thickness in the central foveal $(r=0.08 ; p=0.47)$ or any quadrant in the parafoveal and perifoveal regions $(r=0.01-$ $0.19 ; p=0.09-0.90$ ) was found. This finding is consistent with those of previous studies ${ }^{14,18,49}$ and is most likely because of the inclusion of only healthy non-glaucomatous participants. Hess et al. ${ }^{57}$ reported that the central retina is not affected in healthy individuals in comparison with glaucomatous individuals.

Strengths of the present study include the use of a cohort of young, healthy, myopic adults with an even distribution of age and gender and standardised retinal thickness, 
spectacle refraction and axial length measurement protocols. The Fourier/spectral domain OCT device used an internal fixation target to minimise errors caused by off-centre fixation resulting in falsely elevated central foveal thickness. Possible limitations of the study include participants' selfreporting of race and the inclusion of only two race groups. Limiting the age range of participants implies that the results may not be generalised to older or younger individuals, and the effect of age on retinal thickness measurements could not be studied. Lastly, the low range of axial lengths and spherical equivalents is a possible limitation; it is therefore recommended that future studies include individuals with higher degrees of myopia. The sample in the present study was also fairly small and future studies should attempt to increase the sample size.

The results of the study are important and may help to further understand the high prevalence of certain retinal diseases in specific gender and race groups. For example, females are at higher risk of developing macular holes. ${ }^{58}$ The gender predilection of macular holes may be attributed to thinner retinal thickness measurements in females than in males. In South Africa, diabetes is more prevalent among Indian than black people, ${ }^{59}$ even though the latter are more likely to develop diabetic retinopathy. ${ }^{26,60}$ The racial predilection of diabetic retinopathy may be attributed to thinner retinal thickness in black than in Indian individuals. However, future longitudinal studies are needed to investigate these claims.

\section{Conclusion}

The present study used Fourier/spectral domain OCT to demonstrate racial and gender differences in retinal thickness measurements. The retinal thickness measurements obtained in this study are comparable to some studies but differ from other studies using OCT technology. The present study is believed to be the first published research to provide retinal thickness (macular) measurements in black and Indian individuals of South African origin. As diagnosis of retinal abnormalities, by OCT, depends on comparison with normative values, the study is relevant in that it reports baseline data from healthy individuals within these populations. It is suggested that optometrists and ophthalmologists consider these differences when evaluating black and Indian individuals with retinal diseases.

\section{Acknowledgements}

The authors thank General Optical for the loan of the autorefractor (Nidek AR-1) for the duration of the study. The authors also thank Dr R Hansraj for kindly reviewing the manuscript and providing valuable feedback.

\section{Competing interests}

The authors declare that they have no financial or personal relationships which may have inappropriately influenced them in writing this article.

\section{Authors' contributions}

P.S. (University of KwaZulu-Natal) was the study leader. S.J. (University of KwaZulu-Natal) and N.R. (University of KwaZulu-Natal) provided feedback on the study design. C.M. (University of KwaZulu-Natal), B.Z.G. (University of KwaZulu-Natal), K.P. (University of KwaZulu-Natal), B.N.M. (University of KwaZulu-Natal), P.S. and S.K.M. (University of KwaZulu-Natal) performed the data collection. N.R. wrote the manuscript.

\section{References}

1. Hildebrand GD, Fielde AR. Anatomy and physiology of the retina. In: Reynolds JD, Olitsky SE, editors. Pediatric retina. London: Springer, 2011; pp. 39-66. http:// dx.doi.org/10.1007/978-3-642-12041-1_2

2. Pavan-Langston D. Manual of ocular diagnosis and therapy. 5th edn. Philadelphia: Lippincott Williams \& Wilkins; 2008.

3. Adhi M, Aziz S, Muhammad K, Adhi MI. Macular thickness by age and gender in healthy eyes using spectral domain optical coherence tomography. PLoS One. 2012;7:1-6. http://dx.doi.org/10.1371/journal.pone.0037638

4. Huang $D$, Swanson EA, Lin $P$, et al. Optical coherence tomography. Science. 1991;254:1178-1181. http://dx.doi.org/10.1126/science.1957169

5. Sull AC, Vuong LN, Price LL, et al. Comparison of spectral/Fourier domain optical coherence tomography instruments for assessment of normal macular thickness. Retina. 2010;30:235-245. http://dx.doi.org/10.1097//AE.0b013e3181bd2c3b

6. Huang J, Liu X, Wu Z, Xiao H, Dustin L, Sadda S. Macular thickness measurements in normal eyes with time-domain and Fourier-domain optical coherence tomography. Retina. 2009;29:980-987. http://dx.doi.org/10.1097/IAE.0b013e3181a2c1a7

7. Wagner-Schuman $M$, Dubis $A M$, Nordgren RN, et al. Race- and sex-related differences in retinal thickness and foveal pit morphology. Invest Ophthalmol Vis Sci. 2011;52:625-634. http://dx.doi.org/10.1167/iovs.10-5886

8. Hee MR, Izatt JA, Swanson EA, et al. Optical coherence tomography of the human retina. Arch Ophthalmol. 1995;113:325-332. http://dx.doi.org/10.1001/ archopht.1995.01100030081025

9. Lam DSC, Chan CKM, Mohamed S, et al. Intravitreal triamcinolone plus sequential grid laser versus triamcinolone or laser alone for treating macula edema. Ophthalmol. 2007;114:2162-2167. http://dx.doi.org/10.1016/j. ophtha.2007.02.006

10. Diabetic retinopathy clinical research network. A randomized trial of peribulbar triamcinolone acetonide with and without focal photocoagulation for mild diabetic macular edema: A pilot study. Ophthalmol. 2007;114:1190-1196. http:// dx.doi.org/10.1016/j.ophtha.2007.02.010

11. Puliafito CA, Hee MR, Lin CP, et al. Imaging of macular diseases with optical coherence tomography. Ophthalmol. 1995;102:217-229. http://dx.doi. org/10.1016/S0161-6420(95)31032-9

12. Asrani S, Zou S, d'Anna S, Vitale S, Zeimer R. Noninvasive mapping of the normal retinal thickness at the posterior pole. Ophthalmol. 1999;106:269-273. http:// dx.doi.org/10.1016/S0161-6420(99)90057-X

13. Asefzadeh B, Cavallerano AA, Fisch BM. Racial differences in macular thickness in healthy eyes. Optom Vis Sci. 2007;84:941-945. http://dx.doi.org/10.1097/ OPX.0b013e318157a6a0

14. Kelty PJ, Payne JF, Trivedi RH, Kelty J, Bowie M, Burger BM. Macular thickness assessment in healthy eyes based on ethnicity using Stratus OCT optical coherence tomography. Invest Ophthalmol Vis Sci. 2008;49:2668-2672. http:// dx.doi.org/10.1167/iovs.07-1000

15. Kashani AH, Zimmer-Galler IE, Shah SM, et al. Retinal thickness analysis by race, gender, and age using Stratus OCT. Am J Ophthalmol. 2010;149:496-502. http:// dx.doi.org/10.1016/j.ajo.2009.09.025

16. Grover S, Murthy RK, Brar VS, Chalam KV. Normative data for macular thickness by high-definition spectral-domain optical coherence tomography (Spectralis). Am J Ophthalmol. 2009;148:266-271. http://dx.doi.org/10.1016/j.ajo.2009.03.006

17. Song WK, Lee SC, Lee ES, Kim CY, Kim SS. Macular thickness variations with sex, age, and axial length in healthy subjects: A spectral domain-optical coherence tomography study. Invest Ophthalmol Vis Sci. 2010;51:3913-3918. http://dx.doi. org/10.1167/iovs.09-4189

18. Wong ACM, Chan CWN, Hui SP. Relationship of gender, body mass index and axial length with central retinal thickness using optical coherence tomography. Eye. 2005;19:292-297. http://dx.doi.org/10.1038/sj.eye.6701466

19. Tewari HK, Wagh VB, Sony P, Venkatesh P, Singh R. Macular thickness evaluation using optical coherence tomography in normal Indian eyes. Indian J Ophthalmol. 2004;52:199-204.

20. Girkin CA, McGwin G, Sinai MJ, et al. Variation in optic nerve and macular structure with age and race with spectral-domain optical coherence tomography. Ophthalmol. 2011;118:2403-2408. http://dx.doi.org/10.1016/j. ophtha.2011.06.013

21. Saunders RA, Donahue ML, Christmann LM, et al. Racial variation in retinopathy of prematurity. Arch Ophthalmol. 1997;115:604-608. http://dx.doi.org/10.1001/ archopht.1997.01100150606005 
22. Klein $\mathrm{R}$, Klein $\mathrm{BE}$, Knudtson $\mathrm{MD}$, et al. Prevalence of age-related macular degeneration in 4 racial/ethnic groups in the multi-ethnic study of atherosclerosis. Ophthalmol. 2006;113:373-380. http://dx.doi.org/10.1016/j.ophtha.2005.12.013

23. Chang MA, Bressler SB, Munoz B, West SK. Racial differences and other risk factors for incidence and progression of age-related macular degeneration: Salisbury eye evaluation (SEE) project. Invest Ophthalmol Vis Sci. 2008;49:2395-2402. http:// dx.doi.org/10.1167/iovs.07-1584

24. Eye disease prevalence research group. Prevalence of open-angle glaucoma among adults in the United States. Arch Ophthalmol. 2004;122:532-538. http:// dx.doi.org/10.1001/archopht.122.4.532

25. Stein JD, Kim DS, Niziol LM, et al. Differences in rates of glaucoma among Asian Americans compared with other races and among individuals of different Asian ethnicities. Ophthalmol. 2011;118:1031-1037. http://dx.doi.org/10.1016/j. ophtha.2010.10.024

26. Kalk WJ, Joannou J, Ntsepo S, Mahomed I, Mahanlal P, Becker PJ. Ethnic differences in the clinical and laboratory associations with retinopathy in adult onse diabetes: Studies in patients of African, European and Indian origins.J Intern Med. 1997;241:31-37. http://dx.doi.org/10.1046/j.1365-2796.1997.70892000.x

27. Prakash G, Agarwal A, Jacob S, Kumar DA, Agarwal A, Banerjee R. Comparison of Fourier-domain and time-domain optical coherence tomography for assessment of corneal thickness and intersessional repeatability. Am J Ophthalmol. 2009;148:282-290. http://dx.doi.org/10.1016/j.ajo.2009.03.012

28. Rao HL, Kumar AU, Babu JG, Kumar A, Senthil S, Garudadri CS. Predictors of normal optic nerve head, retinal nerve fiber layer, and macular parameter measured by spectral domain optical coherence tomography. Invest Ophthalmo Vis Sci. 2011;52:1103-1110. http://dx.doi.org/10.1167/iovs.10-5997

29. Huynh SC, Wang XY, Rochtchina E, Mitchell P. Distribution of macular thicknes by optical coherence tomography: Findings from a population-based study of 6-year-old children. Invest Ophthalmol Vis Sci. 2006;47:2351-2357. http://dx.doi. org/10.1167/iovs.05-1396

30. Sato A, Fukui E, Ohta K. Retinal thickness of myopic eyes determined by Spectralis optical coherence tomography. Br J Ophthalmol. 2010;94:1624-1628. http:// dx.doi.org/10.1136/bjo.2009.165472

31. Benjamin WJ. Borish's clinical refraction. 2nd ed. Toronto: Elsevier; 2006.

32. Best N, Drury L, Wolffsohn JS. Clinical evaluation of the Oculus Keratograph Cont Lens Anterior Eye. 2012;35:171-174. http://dx.doi.org/10.1016/j. clae.2012.04.002

33. Mao X, Savini G, Zhuo F, et al. Repeatability, reproducibility, and agreement of corneal power measurements with a new corneal topographer. J Cataract Refract Surg. 2013;39:1561-1569. http://dx.doi.org/10.1016/j.jcrs.2013.04.029

34. Gurler B, Coskun E, Okumus S, Pinero DP, Ozcan E, Erbagci I. Surgical outcomes of isolated lens coloboma with or without cataract among young adults. Can J Ophthalmol. 2014;49:145-151. http://dx.doi.org/10.1016/j. jcjo.2013.12.004

35. Yannakorpantana K. Comparison of the post-operative visual outcomes between contact technique and immersion technique in intraocular lens power calculation. Region 4-5 Med J. 2012;31:223-228.

36. Optovue Inc. iVue 100 user's manual version 2.6. [cited 2014 Nov 24]. Available from: http://license.optovue.com/CommonFolder/3360/Optovue/580-44218008_A.pdf

37. Early Treatment Diabetic Retinopathy Study Research Group. Early treatmen diabetic retinopathy study design and baseline patient characteristics. ETDRS report number 7. Ophthalmol. 1991;98:741-756. http://dx.doi.org/10.1016/ S0161-6420(13)38009-9

38. Giani A, Cigada M, Choudary N, et al. Reproducibility of retinal thickness measurements on normal and pathological eyes by different optical coherence tomography instruments. Am J Ophthalmol. 2010;150:815-824. http://dx.doi. org/10.1016/j.ajo.2010.06.025

39. Ho J, Sull AC, Vuong LN, et al. Assessment of artifacts and reproducibility across spectral and time-domain optical coherence tomography devices. Ophthalmol. 2009;116:1960-1970. http://dx.doi.org/10.1016/j.ophtha.2009.03.034

40. Paunescu LA, Schuman JS, Price LL, et al. Reproducibility of nerve fiber thickness, macular thickness and optic nerve head measurements using Startus OCT. Invest Ophthalmol Vis Sci. 2004;45:1716-1724. http://dx.doi.org/10.1167/ iovs.03-0514
41. Harb E, Hyman L, Fazzari M, Gwiazda J, Marsh-Tootle W, The COMET study group. Factors associated with macular thickness in the COMET myopic cohort. Optom Vis Sci. 2012;89:620-631. http://dx.doi.org/10.1097/OPX.0b013e318251293a

42. Chauhan DS, Marshall J. The interpretation of optical coherence tomography images of the retina. Invest Ophthalmol Vis Sci. 1999;40:2332-2342.

43. Hu DN, Simon JD, Sarna T. Role of ocular melanin in ophthalmic physiology and pathology. Photochem Photobiol. 2008;84:639-644. http://dx.doi.org/10.1111/ j.1751-1097.2008.00316.x

44. Pierro L, Giatsidis SM, Mantovani E, Gagliardi M. Macular thickness interoperator and intraoperator reproducibility in health eyes using 7 optical coherence tomography instruments. Am J Ophthalmol. 2010;150:199-204. http://dx.doi. org/10.1016/j.ajo.2010.03.015

45. Mitkova-Hristova VT, Konareva-Kostyaneva MI. Macular thickness measurements in healthy eyes using spectral optical coherence tomography. Folia Med. 2011;53:28-33. http://dx.doi.org/10.2478/v10153-011-0064-z

46. Forooghian F, Cukras C, Meyerle CB, Chew EY, Wong WT. Evaluation of time domain and spectral domain optical coherence tomography in the measurement of diabetic macular edema. Invest Ophthalmol Vis Sci. 2008;49:4290-4296. http://dx.doi.org/10.1167/iovs.08-2113

47. Wexler A, Sand T, Elsås TB. Macular thickness measurements in healthy Norwegian volunteers: An optical coherence tomography study. BMC Ophthalmol. 2010;10:1-9. http://dx.doi.org/10.1186/1471-2415-10-13

48. El-Ashry M, Hegde V, James P, Pagliarini S. Analysis of macular thickness in British population using optical coherence tomography (OCT): An emphasis on interocular symmetry. Curr Eye Res. 2008;33:693-699. http://dx.doi. on interocular symmetry. Curr
$\mathrm{org} / 10.1080 / 02713680802323140$

49. Zhang Z, He X, Zhu J, Jiang K, Zheng W, Ke B. Macular measurements using optical coherence tomography in healthy Chinese school age children. Invest Ophthalmol Vis Sci. 2011;52:6377-6383. http://dx.doi.org/10.1167/iovs.11-7477

50. Weihong $Y$, Lin Z, Rongping D, Zhiqiao Z, Fangtian D. Macular thickness of Chinese with Fourier-domain optical coherence tomography. Acta Ophthalmol. 2011;89:104-105. http://dx.doi.org/10.1111/j.1755-3768.2010.01864.x

51. Chan A, Duker JS, Ko TH, Fujimoto JG, Schuman JS. Normal macular thickness measurements in healthy eyes using Stratus optical coherence tomography. Arch Ophthalmol. 2006;124:193-198. http://dx.doi.org/10.1001/archopht.124.2.193

52. Wu PC, Chen YJ, Chen $\mathrm{CH}$, et al. Assessment of macular retinal thickness and volume in normal eyes and highly myopic eyes with third-generation optical coherence tomography. Eye. 2008;22:551-555. http://dx.doi.org/10.1038/sj.eye.6702789

53. Choi SW, Lee SJ. Thickness changes in the fovea and peripapillary retinal nerve fiber layer depend on the degree of myopia. Korean J Ophthalmol. 2006;20:215-219. $\mathrm{http}: / / \mathrm{dx}$.doi.org/10.3341/kjo.2006.20.4.215

54. Curtin BJ, Karlin DB. Axial length measurements and fundus changes of the myopic eye. Am J Ophthalmol. 1971;71:42-53. http://dx.doi.org/10.1016/0002 9394(71)91092-0

55. Karlin DB, Curtin BJ. Peripheral chorioretinal lesions and axial length of the myopic eye. Am J Ophthalmol. 1976;81:625-631. http://dx.doi.org/10.1016/00029394(76)90129-X

56. Wakitani $Y$, Sasoh $M$, Sugimoto $M$, Ito $Y$, Ido $M$, Uji $Y$. Macular thickness measurements in healthy subjects with different axial lengths using optical coherence tomography. Retina. 2003;23:177-182. http://dx.doi. org/10.1097/00006982-200304000-00007

57. Hess DB, Asrani SG, Bhide MG, Enyedi LB, Stinnett SS, Freedman SF. Macular and retinal nerve fiber analysis of normal and glaucomatous eyes in children using optical coherence tomography. Am J Ophthalmol. 2005;139:509-517. http:// dx.doi.org/10.1016/j.ajo.2004.10.047

58. McCannel CA, Ensminger JL, Diehl NN, David N, Hodge MS. Population based incidence of macular holes. Ophthalmology. 2009;116:1366-1369. http://dx.doi org/10.1016/j.ophtha.2009.01.052

59. Bradshaw D, Norman R, Pieterse D, Levitt NS, South African Comparative Risk Assessment Collaborating Group. Estimating the burden of disease attributable to diabetes in South Africa 2000. S Afr Med J. 2007;97:700-706. http://dx.doi.org/1 0.1080/22201009.2007.10872159

60. Motala AA, Pirie FJ, Gouws E, Amod A, Omar MA. Microvascular complications in South African patients with long-duration diabetes mellitus. S Afr Med J. 2001;91:987-992. 